Portland State University

PDXScholar

\title{
Community-Based Participatory Research with Communities Defined by Race, Ethnicity, and Disability: Translating Theory to Practice
}

Christina Nicolaidis

Portland State University, christina.nicolaidis@pdx.edu

Dora Raymaker

Portland State University, draymake@pdx.edu

Follow this and additional works at: https://pdxscholar.library.pdx.edu/socwork_fac

Part of the Social Work Commons

Let us know how access to this document benefits you.

\section{Citation Details}

Nicolaidis, Christina and Raymaker, Dora, "Community-Based Participatory Research with Communities Defined by Race, Ethnicity, and Disability: Translating Theory to Practice" (2015). School of Social Work Faculty Publications and Presentations. 368.

https://pdxscholar.library.pdx.edu/socwork_fac/368

This Book Chapter is brought to you for free and open access. It has been accepted for inclusion in School of Social Work Faculty Publications and Presentations by an authorized administrator of PDXScholar. Please contact us if we can make this document more accessible: pdxscholar@pdx.edu. 
NOTICE: this is the author's version of a work that was accepted for publication in the Sage Handbook of Action Research. Changes resulting from the publishing process, such as peer review, editing, corrections, structural formatting, and other quality control mechanisms may not be reflected in this document. Changes may have been made to this work since it was submitted for publication. A definitive version was subsequently published in Bradbury (ed.) The Sage Handbook of Action Research. 2015. Sage Publications, LTD. Thousand Oaks, CA. Pp 167-178.

Community Based Participatory Research with communities defined by race, ethnicity, and disability: Translating theory to practice.

Christina Nicolaidis

Dora Raymaker

Corresponding author: Christina Nicolaidis, MD, MPH, Professor, School of Social Work, Portland State University, 1600 SW $4^{\text {th }}$ Ave, Suite 900, Portland, OR 97201. Nicol22@pdx.edu. 


\section{Introduction}

Community based participatory research (CBPR) is an increasingly popular participatory research approach where community members and academics collaborate as equal partners to conduct research for improving health and wellbeing through action (Isreal et al., 2003; Wallerstein \& Duran, 2003). It is a branch of action research in the tradition of emancipatory practice. CBPR grew within the health sciences in the 1990's in response to a number of issues with mainstream health science research and minority communities, including lack of representation in research, lack of health science research that met community goals, lack of consideration of environmental factors as social determinants of health, and a history of exploitation in science. CBPR has since become a major approach to inquiry within the health sciences, with agencies such as the National Institutes of Health and the US Department of Health and Human Services having dedicated CBPR sections. While it evolved within the health sciences, the approach or practice, like other action research practices, can be used in any field.

At the heart of CBPR lies a foundation of nine principles (Isreal et al., 2003) and four considerations for facilitating emancipatory practice (Wallerstein \& Duran, 2003). (See Box 1.) CBPR takes a holistic, systems approach to its practice. Although the principles and considerations provide the basic foundation of CBPR practice, they are not intended to be taken dogmatically but within the context of each partnership and project to which they are applied; to that end, they can be adjusted if needed for a particular collaboration (Isreal et al., 2003).

\section{[Insert Box 1 around here.]}

In this chapter, we tie the theoretical principles of CBPR to practice via examples drawn from our work across three projects: the Interconnections Project / Proyecto Interconexiones (Interconnections), the Academic Autistic Spectrum Partnership in Research and Education (AASPIRE), and the Partnering with People with Developmental Disabilities to Address Violence project (Partnering). We discuss the four essential components of CBPR--a focus on community, equal partnerships, research for action, and an ongoing commitment to its principles--with examples of how they have played out in our practice.

\section{Our Projects}

The Interconnections project / Proyecto Interconexiones, grew out of a traditional nonparticipatory research project to create a health-system-based depression program for intimate partner violence (IPV) survivors. After it became clear that the project was not adequately addressing the needs of women of color, the principal investigator (PI; this chapter's first author), approached leaders of the African-American and Latino communities in Portland, Oregon to assess their interest in using a CBPR approach to adapt the existing project. They were enthusiastic about addressing depression and IPV, but suggested creating a new project to develop community-based programs specifically targeted to women of color. The partnership worked together for seven years, during which time we conducted two focus group studies (Nicolaidis, Perez, et al., 2011; Nicolaidis et al., 2010) and created and pilot-tested two community-based depression interventions for African-American (Nicolaidis, Wahab, et al., 2013) and Latina (Nicolaidis, Mejia, et al., 2013) IPV survivors. Both pilot interventions 
demonstrated large, statistically significant improvements in depression severity, self-efficacy, and self-esteem.

The Academic Autistic Spectrum Partnership in Research and Education (AASPIRE, www.aaspire.org) started in 2006 when this chapter's co-authors--a clinician/researcher and an Autistic person--met to review autism research articles. As we evaluated the research, we found ourselves questioning the ethics, value, and validity of the work. Little research focused on issues the Autistic community cared about, the language and framing of the studies was disrespectful and stigmatizing, study designs failed to account for important characteristics of autism, and interpretations of data jarred with the lived-experiences of autistic persons (Raymaker \& Nicolaidis, 2013). We began AASPIRE with a long-term commitment to the Autistic community and with a mission to equitably include autistic individuals in autism research and to conduct studies desired by the Autistic community (Nicolaidis, Raymaker, et al., 2011). Among other projects, AASPIRE has conducted a series of healthcare studies focusing on healthcare disparities experienced by autistic adults (Nicolaidis, Raymaker, et al., 2013), the qualitative experiences of autistic adults and other stakeholders in healthcare, and the development and evaluation of a healthcare toolkit for autistic adults, their supporters, and primary care providers (www.autismandhealth.org).

\section{The Partnering with People with Developmental Disabilities to Address Violence} (Partnering) project began when the Centers for Disease Control put out a request for proposals to study the relationship between health, violence, and disability in people with developmental disabilities. Given significant challenges in obtaining accurate data about violence in people with developmental disabilities, we and our collaborators at the University of Montana and Portland State University felt that the only way to adequately achieve this goal was by using a CBPR approach to include people with developmental disabilities in conducting the study. We asked leaders in the community if they would be interested in partnering with us, and due to the high priority the developmental disabilities community places on addressing violence, they agreed. The resulting community-academic partnership collaborated to adapt instruments to be accessible to people with developmental disabilities (Nicolaidis et al., 2014 in press), created an accessible audio-computer assisted survey instrument (ACASI) (Oschwald et al., 2014), and used it to survey 350 adults with developmental disabilities. The adapted scales demonstrated strong psychometric properties; the vast majority of participants found the ACASI easy to use; and though over $60 \%$ of participants disclosed a history of abuse, our approach allowed us to obtain this data anonymously without the need for any mandatory reporting.

\section{Putting the essential properties of CBPR into practice}

The essential properties of CBPR are a focus on: 1) community, 2) equal partnerships, 3) research for action, and 4) on-going commitment to the principles of CBPR. Keeping these essential foci in scope is no trivial task, and there exists no simple formula to achieve them. Strategies will be specific to the research context, project, community, and individuals involved. However, we have found through the diversity of our projects some underlying considerations which have helped guide us in the development of individualized strategies for conducting CBPR. In this section we share lessons we have learned, as well as those underlying considerations that translate into other CBPR contexts. 
CBPR, by definition, focuses on a community. The principles specifically ask teams to acknowledge the community as a unit of identity and to build on community strengths and resources (see Box 1). This focus helps empower the community. By treating the community as a unit of identity, the community can have much greater power than any single community member may otherwise have if invited to participate in a research team. Similarly, the use of community strengths and resources, which is generally translated to mean partnering with existing community organizations and leaders, protects against academic researchers purposefully or inadvertently doing work that goes against the community's shared values or goals. CBPR projects are traditionally based in community organizations or settings. A form of CBPR, Community Partnered Participatory Research (CPPR) espouses principles of CBPR with equal rigor, but acknowledges that projects may sometimes be based in university settings or the healthcare system (Jones \& Wells, 2007).

In theory, a community is defined as a group of individuals with a shared history, value system, symbol set, language, and sense of culture and identity (Isreal et al., 2003). Defining a "community" in practice can pose significant challenges. Even readily identified communities, such as those defined by race or ethnicity, are never monolithic; even seemingly-homogeneous units can have sub-groups or political factions. In Interconnections, for example, we inadvertently created tensions by working with some African American and Latino communitybased organizations and leaders and not others.

Defining the community can be even more challenging in other settings. Communities defined by race or ethnicity typically follow family lines. However, some communities, such as the Autistic, lesbian/gay/bisexual/transgender (LGBT), or Deaf communities, follow a different pattern whereby community members come from predominantly non-autistic, heterosexual, or hearing families, respectfully. Family members are important stakeholders, but the values of family members can be in direct opposition to the values of the minority community. For example, though parents of autistic individuals dominate the traditional "autism community", many autistic individuals have voiced strong opposition to parent-run autism organizations, arguing that their focus on finding a "cure" for autism and making people aware of what a devastating effect autism has on families is dehumanizing and harmful to autistics ( $\mathrm{Ne}$ 'eman, 2010). AASPIRE has chosen to focus on the priorities of the self-advocacy community, welcoming family members as important stakeholders, as long as they are interested in supporting the self-advocate-focused mission of the partnership.

Some CBPR projects may necessitate partnering with broader populations that include multiple different communities. In the case of Partnering, we were interested in working with people with a broad range of developmental disabilities. As such, we formally partnered with communitybased organizations that focused on specific disabilities (autism, intellectual disabilities) and ones that had a more cross-disability focus. We found that inclusion of both leaders and representatives from each disability community was critical to ensuring the project met the needs of the larger population.

\section{Equitable Partnership}

The Meaning of "Equitability" in CBPR

CBPR focuses on equal partnerships. "Equal" does not mean "the same." Equal weight and consideration is given to the contributions of both the community and academic partners, but the 
nature of those contributions covers different areas. Community partners are not expected to become statisticians; likewise, academic partners are not expected to be experts on community politics and concerns. The community is primarily responsible for ensuring research is respectful, accessible, and socially relevant. The academics are primarily responsible for ensuring the research is scientifically sound and academically relevant. This is true at every phase of the research process--from development to implementation to dissemination--as community and academic partners weave together their collective expertise to conduct research that balances knowledge generation and action for the mutual benefit of all partners. (See Figure 1.)

Equal partnership means ideas for research can be initiated by anyone, but must be both important to the community and relevant to science. AASPIRE's projects are typically chosen by negotiating intersections of the many research areas the community would like explored with the group's academic expertise. In the case of Partnering, academic partners brought the idea to the community. Interconnections grew out of a complex interaction between research gaps and community needs. There is no one way to initiate a partnership, but the project must have equal relevance to all partners.

Equal partnership also means balancing scientific rigor and community control. If community partners suggest something that could compromise the science, academic partners should explain the potential issues and recommend alternatives; it is important that scientific concerns be fully disclosed in lay terms so that informed decisions can be made by all partners. On the other side, equal partnership means that the community has true control in the research; community members are neither tokens nor advisors but co-creators in the research process.

\section{Strategies for Obtaining Equitability in CBPR}

Drawing these concepts of equitability into practice requires great attention to structure, process, and continuous reflection and adjustment. There is no simple formula for achieving equitability; the structures, processes, and mechanisms for evaluation that support emancipatory research vary with the needs of the project, the community, and the individuals involved. However, we have, through the course of our work, learned the following key considerations that underlie the selection and development of strategies for equitable partnership.

Leadership structures and organizational roles impact capacity for equitable practice. We have come to use a variety of structures to facilitate equitability. Those structures have evolved over time and have manifested differently in each project to match the group's context and needs. While there is no one perfect infrastructure for CBPR projects, it is important to consider infrastructure carefully as it has an impact on equitable involvement and project success.

Given the small number of people involved, Interconnections started as a single team without formal organizational structures. We later amicably split into separate African-American and Latina teams due to efficiency issues and added additional research assistants and academic and community partners to meet study goals. However the groups remained small enough that academic and community partners could work together informally as "team members". The benefits of a relatively simple working arrangement in this case had to be balanced against the lack of more formal structures for ensuring power sharing.

As a larger and more diffuse organization involved in multiple ongoing activities, AASPIRE initially tried a complex infrastructure with individual workgroups, but the structure was confusing 
and disempowering for all team members. AASPIRE now uses an organizational model with community and academic co-principal investigators (co-PIs), a community council and academic council, and a steering committee made of the co-Pls, two community representatives, and one academic representative. The steering committee provides conflict-resolution and makes decisions in rare situations where we are unable to involve the whole team due to time constraints. We have found this structure helpful in balancing power because it includes community co-control at all organizational levels.

Partnering was a multi-site partnership with formal relationships between multiple universities and community-based organizations. As such, we created an infrastructure consisting of a project-level Steering Committee (three academic PIs, two project managers, and four community-based organization representatives who themselves are people with disabilities) and local Community Advisory Boards (four people with disabilities, a family member and a disability services professional) at each site. As described below, due to accessibility issues we split into two local Steering Committees that could meet in-person, with the PIs communicating between sites and obtaining input from other academic consultants. The Steering Committees jointly made higher-level decisions and prepared materials for use by the Community Advisory Boards. The Community Advisory Board for each site met with the local Steering Committee Members to conduct the work of the study. This structure has allowed for multiple ongoing checks and balances between community and academic partners.

Processes for shared decision-making must attend to power, discourse, and reflection. Co-learning and equability are impossible without a process for shared decision-making that supports them. We were fortunate to have found a process (what in the Handbook might be referred to as a "skill") for shared decision-making that has worked extremely well across all of our projects. The five-finger method for decision-making is an iterative, feedback-driven method for group decision-making that we use as an alternative to voting (Nicolaidis, Raymaker, et al., 2011). The method asks decision-makers to indicate degree of approval (one or two fingers), the need for more discussion (three fingers), or degree of disapproval along with their reasons (four or five fingers). This method has multiple benefits over voting schemes. First, its iterative and reflective nature enables the refinement and improvement of proposed ideas by encouraging discussion and critical reflection. Second, it ensures everyone is given an equal opportunity to express their feelings and have their questions answered. Third, it enables people to express the degree of their feelings about an item, including having an outlet to disapprove of an item without blocking it (four fingers), which facilitates a speedier resolution of decisions. As a relevant illustration of this method in-use, during Partnering we used it recursively to decide whether or not we wanted to use it. One of our community partners gave the idea four fingers-she did not want to use it. When describing why she said it was because holding up fingers was childish; to an adult who had been infantilized as a form of oppression, holding up fingers was problematic. This deeper understanding enabled us as a group to modify the process to one where people had an option to say their number instead of holding up fingers. When we asked again what team members thought of using the decision-making process, she approved it. More traditional voting schemes would have missed the cultural components at play, as well as the capacity to adjust the process and remedy the issue. While this method may not be the best choice for all groups, a method for shared decision-making that facilitates equitable discourse and reflection can overcome some of the barriers to power-sharing that are inherent in voting processes.

Communication methods that privilege the community are necessary to balance power and enable effective community control. In some projects, it is fairly obvious that communication must happen in the language of the community. For example, in the 
Interconnections project, we used simultaneous translation in joint meetings with Latino and African-American teams and held meetings in Spanish when meeting with the Latino team separately. Communication extends beyond language, though. The AASPIRE team is geographically dispersed and includes many community partners who cannot effectively communicate by telephone. As such, we have always communicated online, via email or instant messenger (IM) chat. This mode places non-autistic partners who are used to communicating in speech at a disadvantage, privileges our Autistic community partners (who tend to be more comfortable with online communications), and enables autistic partners to have more control of the work (Nicolaidis, Raymaker, et al., 2011). For Partnering however, our diverse set of community and academic partners included individuals for whom reading and/or writing would have been a barrier to participation. We attempted to hold multi-site team meetings over conference calls, but community partners, many of whom had trouble thinking or speaking quickly, were left out of the conversations. To remedy this, we changed our infrastructure to hold team meetings in-person at each site and tasked project staff with ensuring communicating between the two sites. It was in-person meetings with communication-related accommodations (e.g., providing ASL interpreters, slowing the pace of communication, assigning a "process monitor" to ensure that everyone had a chance to be heard) that equalized communication between community and academic members of the team. Communication issues are not limited to those related to disability or language, but also include differences in the social aspects of how community and academic partners communicate. For Interconnections, abandoning a business-like all-work meeting agenda in favor of one that included social activities was necessary for building trust and a generating a collaborative environment.

Collaboratively-developed processes and procedures facilitate equitable participation at all stages of the research. Though Interconnections relied primarily on informal (and sometimes unstated) agreements between partners, AASPIRE and Partnering have developed formal authorship and presentation policies. (See Appendix.) These policies specify how academics and community members are to be actively involved in the authorship process, and include both academic and community dissemination paths. Both groups also maintain operational guidelines with items community members have determined they require to participate equitably in the work; for example, Partnering's guidelines include disability accommodations such as using natural lighting (to accommodate the sensory sensitivities of autistic partners) and stating one's name before speaking (to accommodate a blind partner) in addition to more general items like respecting confidentiality and ensuring everyone is included. These formal agreements have been useful in ensuring community inclusion and avoiding misunderstandings.

Projects must be jointly owned and co-created in all stages of the research process from inception to dissemination. As pictured in Figure 1, community and academic partners are involved in all stages of the research process from idea development through to the end of dissemination and into plans for next steps. As discussed under the meaning of equitability, this does not necessarily mean they are doing the same work (although in some cases it might). It is important to be respectful of community members' time, to compensate them fairly for their time, and to consider which aspects of the work are worth their time; we task research staff with formatting and packaging research materials in such a way as to minimize "busy work" so that our community partners can focus on directing the research, making decisions, and having a real impact on the work we produce. Using these strategies, community partners collaborated with academic partners to 1) create study protocols and recruitment and consent materials (all projects); 2) create interview guides (AASPIRE and Partnering) and create or adapt survey instruments (all projects); 3 ) facilitate focus groups and collect survey data (Interconnections) and conduct qualitative interviews (AASPIRE); 4) code and analyze qualitative data 
(Interconnections and AASPIRE); and 5) interpret quantitative results (all projects). Community partners also have served as co-authors on all publications and have directly disseminated findings to the community in special community-focused events, blogs, and/or newsletters in all three projects.

\section{[Insert Figure 1 about here.]}

\section{Translation activities are critical to making the research accessible and understandable}

to all partners. In Proyecto Interconexiones this meant literally translating materials into Spanish. In AASPIRE and Partnering it has meant translating concepts and materials into plain language that is understandable to individuals with intellectual and/or communication disabilities. For AASPIRE this chapter's second author holds an intersectional space between community and academic perspectives and translates and bridges materials. In Partnering, where we had a diverse group of community partners with at times competing accommodation needs, community members of the Steering Committee helped the academics translate and package information. For example, in order to allow community partners to authentically serve as co-authors on scientific papers, we created plain language translations of draft manuscripts that could be reviewed side by side with the scientific text. In all 3 projects academic team members explained scientific concepts to community partners in lay terms so that they could decide what to include as predictors, confounders, moderators, and primary, secondary and intermediate outcomes in quantitative analyses. However it is achieved, in order for all members of the CBPR team to be able to collaborate equitably on the project, the project must be run with sufficient transparency so that everyone is able to act on the same information.

Equitability requires continuous reflection, evaluation, and adjustment. Finding structures and processes that work can take multiple iterations. Scientists can be unaware of the privilege they hold, or, as with the perception of the five-finger method as childish, fail to understand community context. When committed to a long-term process and group sustainability, team members, projects, and research contexts change, and processes may need to change along with them. We have used a variety of methods for reflection and adjustment, some formal and others woven into the daily fabric of our work.

AASPIRE was founded on an emancipatory version of the learning organization model which incorporates feedback to generate "an organization that is continually expanding its capacity to create its future" (Senge, 1990). As such, we've always attempted to maintain a culture of openness, reflection, and safety in inquiry and advocacy to foster fluid feedback mechanisms for evaluating and improving our processes. We do explicit "CBPR check-ins" at the end of our meetings when needed or when there is time, as well as when there are specific reasons to do so (e.g., new process, new phase of the project, new collaborators). Partners are also encouraged to provide feedback unsolicited, as was the case when one of our community members spoke up about her difficulty with team emails and recommended a new format that we are still using successfully six years later.

The Interconnections Project had originally been less pro-active in soliciting feedback, but both the African-American and Latina teams held special meetings to resolve conflict in response to unanticipated problems. Over time, the African-American side of the project also created a number of process for evaluation, including providing anonymous index cards for feedback at the end of African-American team meetings and conducting an internal survey and qualitative inquiry about team dynamics.

While the Partnering project employed mechanisms for continuous feedback (a plus/delta 
activity at the end of each meeting) and a yearly review of group guidelines, it also employed an external program evaluator to conduct yearly evaluations of the project. Her findings gave us important insights, such as better understanding the inequities created by the conference calls and how well the structural fix we implemented to address them worked.

Although unique from each other and shaped by the project and community context, all of these approaches were effective at helping us identify, understand, and improve our CBPR processes.

\section{Research for Action}

CBPR, as a practice of action research, also places primacy on action. Action can occur on multiple levels, from skill-building of individual team members to wide-scale systems change. Action can occur along many vectors, including informing intervention, informing policy, capacitating community, and influencing science and the academy. The Interconnections Project hosted three large depression and domestic violence awareness events in the community that reflected the themes from the focus groups (e.g., the archetype of a strong black woman as a barrier to recognizing and treating depression) translated into art, spoken word, and performance. AASPIRE has produced a public healthcare toolkit for community use (autismandhealth.org). It also operates as a consulting service for autism researchers who want to involve the community but do not have the ability to develop their own CBPR partnership; this in turn broadens the impact the Autistic community has on autism research. More personally, community capacitation has enabled this chapter's second author to obtain her PhD, bringing more Autistic voice into the academy.

How research is translated into action may capitalize on strengths of the community partners. The Interconnections team included a well-known artist and performer whose skills and reputation were critical to the success of community events and the AASPIRE team included an information technology professional whose experience and skills were necessary for the creation of the online toolkit. However it manifests, CBPR calls for the research to extend beyond science and into the broader context surrounding the science to generate change that is desired by the community.

\section{Ongoing Commitment to the Principles of CBPR}

Successful partnerships require ongoing commitment to the principles of CBPR. Trust, colearning, and power-sharing take time to build, and take vigilance and effort to maintain. Though structures and processes can be helpful, ultimately what makes a partnership work is the partners' commitment to finding ways to equitably work together. Each of our projects experienced significant challenges, sometimes related to expected struggles between academics and community members, but also due to circumstances outside of the partnership. Tensions within organizations, between community members and leaders, and between the academic partners themselves can also affect a project. In Interconnections, during the seven years we worked together, both our partnering community-based organizations experienced multiple changes in organizational leadership with a total of seven different executive directors and three project managers being on our team at different times. Trust cannot be taken for granted, even when it exists. In both AASPIRE and Proyecto Interconexiones, we were so used to a deep level of familiarly and trust between existing team members that we failed to adequately attend to the change in group dynamics when bringing on new partners partway 
through the projects. This caused friction until we actively worked to rebuild trust. Ultimately, though, each project was successful, largely because the individuals involved were willing to work through challenges and learn from each other.

\section{Conclusions}

CBPR is a practice of action research that is distinguished through its combination of four essential elements: 1) a focus on community, 2) equitable partnerships, 3) the use of research for action, and 4) an on-going commitment to upholding its principles. Equitability in CBPR means evolving a balance of power and a balance of contribution between community and academic partners. Facilitating CBPR requires attention to infrastructures, decision-making processes, communication, operating procedures, research implementation processes, and feedback mechanisms for reflection and improvement. The nine principles of CBPR and four considerations for emancipatory practice serve as underlying guides for systematically drawing theory into practice (see Box 1). Though each project will require its own set of infrastructures and processes to meet its specific needs, attention to the essential elements can help teams work toward the emancipatory goals that brought them together.

CBPR requires considerable time, effort, and long-term commitment. Anyone interested in forming a CBPR partnership needs to consider whether or not the resources and dedication exist--both within the community and among the academics--to support the effort. But we feel that the resulting research process and products are well worth the additional time, effort, and commitment.

We have found CBPR to be an effective approach for emancipatory action research with a diverse set of communities defined by race, ethnicity, and ability. Although CBPR has evolved within, and largely been used within, the field of public health, we recommend it for research with marginalized communities in any field. As a practice within the larger family of action research, CBPR practitioners can also benefit from advancement within the larger community of action research. 


\section{Acknowledgements}

We would like to thank the Interconnections, AASPIRE, and Partnering Project teams, including Stephanie Wahab, PhD, Angie Mejia, MA, Mary Jo Thomas, A. Star Waters, S. Renee Mitchell, Vanessa Timmons, Jamie Trimble, Marlen Perez, Anabertha Alvarado, Rosemary CelayaAlston, Yolanda Quintero, Raquel Aguillon (Interconnections); Elesia Ashkenazy, Katherine McDonald, PhD, Sebastian Dern, W. Cody Boisclair, PhD, Steven Kapp, Amanda Baggs, Michael Weiner, MD, MPH, Clarissa Kripke, MD, Toby Rates, Martha Gerrity, MD, MPH (AASPIRE); and Rosemary Hughes, PhD, Laurie Powers, PhD, Marsha Katz, MA, Mary Oschwald, PhD, Darren Larson, Eddie Plourde, Lisa Howard, Elesia Ashkenazy, Leanne Beers, Mark Boatman, Gail Bernice Gardner, Nicole Gray, Leah Grantham, James Larocque, Mary Millin, Sherrie Osbourne, Janice Salomon, Albert Star, Andrew Tedlow, Annie Wallington, Mary Ann Curry, RN, DNSc, Susan Robinson-Whelen, PhD, Rebecca Goe, Sandi Leotti, and Emily Lund (Partnering Project).

The Interconnections Project was funded by the National Institutes of Health (1R21MH082139; K23 MH073008; PI Nicolaidis) and Northwest Health Foundation Kaiser Permanente Community Fund (\#10571; PI Nicolaidis)

AASPIRE was funded by the National Institute of Mental Health (1R34MH092503-01; PI Nicolaldis) and the Oregon Clinical and Translational Research Institute (OCTRI), grant number (UL1TR000128) from the National Center for Advancing Translational Sciences (NCATS) at the National Institutes of Health (NIH).

The Partnering Project was funded by the Centers for Disease Control / Association of University Centers on Disabilities (RTOI; PI Hughes).

The content is solely the responsibility of the authors and does not necessarily represent the official views of the funding agencies. 


\section{Author Biographies}

Christina Nicolaidis, MD, MPH is a general internist and health equity researcher interested in participatory approaches to improve the health of marginalized communities. She is Professor and Senior Scholar of Social Determinants of Health at Portland State University, Adjunct Associate Professor of Medicine and Public Health and Preventive Medicine at Oregon Health \& Science University, and Co-Director of the Academic Autism Spectrum Partnership in Research and Education (AASPIRE).

Dora M. Raymaker, MS is a systems scientist and an Autistic self-advocate with an interest in the dynamics at the of intersection of science, technology, and policy; she is a doctoral candidate in the Systems Science program at Portland State University and Co-director of the Academic Autistic Spectrum Partnership in Research and Education (AASPIRE). 
Key References

Isreal, B. A., Schulz, A. J., Parker, E. A., Becker, A. B., III, A. J. A., \& Guzman, J. R. (2003). Critical issues in developing and following community based participatory research principles. In N. W. Meridith Minkler (Ed.), Community-Based Participatory Research for Health (pp. 53-73). San Fransisco, CA: John Wille \& Sons, Inc.

Jones, L., \& Wells, K. (2007). Strategies for Academic and Clinician Engagement in Community-Participatory Partnered Research. JAMA, 297, 407-410. doi: 10.1001/jama.297.4.407

Ne'eman, A. (2010). The future (and past) of autism advocacy, or why the ASA's magazine, The Advocate, wouldn't publish this piece. Disability Studies Quarterly, 30(1).

Nicolaidis, C., Mejia, A., Perez, M., Alvarado, A., Celaya-Alston, R., Quintero, Y., \& Aguillon, R. (2013). Proyecto Interconexiones: A pilot test of a community-based depression care program for Latina violence survivors. Progress in community health partnerships: research, education, and action, 7(4), 395-401.

Nicolaidis, C., Perez, M., Mejia, A., Alvarado, A., Celaya-Alston, R., Galian, H., \& Hilde, A. (2011). "Guardarse las cosas adentro" (keeping things inside): Latina violence survivors' perceptions of depression. Journal of General Internal Medicine, 26(10), 1131-1137.

Nicolaidis, C., Raymaker, D., Katz, M., Oshwald, M., Goe, R., Leotti, S., . . Powers, L. E. (2014 in press). Participatory research to adapt measures of health and interpersonal violence for use by people with developmental disabilities. Progress in community health partnerships: research, education, and action.

Nicolaidis, C., Raymaker, D., McDonald, K., Dern, S., Ashkenazy, E., Boisclaire, W. C., ... Baggs, A. (2011). Collaboration strategies in non-traditional CBPR partnerships: lessons from an academic-community partnership with autistic self-advocates. Progress in community health partnerships: research, education, and action, 011:5(2), 143-150.

Nicolaidis, C., Raymaker, D., McDonald, K., Dern, S., Boisclair, W. C., Ashkenazy, E., \& Baggs, A. (2013). Comparison of healthcare experiences in autistic and non-autistic adults: A cross-sectional online survey facilitated by an academic-community partnership. Journal of General Internal Medicine, 28(6), 761-769. doi: 10.1007/s11606-0132427-z

Nicolaidis, C., Timmons, V., Thomas, M. J., Waters, A. S., Wahab, S., Mejia, A., \& Mitchell, S. R. (2010). "You Don't Go Tell White People Nothing": African American women's perspectives on the influence of violence and race on depression and depression care. American Journal of Public Health, 100(8), 1470-1476.

Nicolaidis, C., Wahab, S., Trimble, J., Mejia, A., Mitchell, S. R., Raymaker, D., ... Waters, A. S. (2013). The interconnections project: development and evaluation of a communitybased depression program for African American violence survivors. Journal of General Internal Medicine, 28(4), 530-538.

Oschwald, M., Leotti, S., Raymaker, D. M., Katz, M., Goe, R., Harviston, M., . . . the Partnering with People with Disabilities to Address Violence Consortium. (2014). Development 
of an Audio-Computer Assisted Self-Interview to investigate violence and health in the lives of people with developmental disabilities. Disabil Health J.

Raymaker, D., \& Nicolaidis, C. (2013). Participatory research with autistic communities: Shifting the system. In J. Davidson, Orsini, M. (Ed.), Worlds of Autism. Minneapolis: University of Minnesota Press.

Senge, P. (1990). The fifth discipline: The art and practice of the learning organization (pp. 174-204). New York: Doubleday/Currency.

Wallerstein, N., \& Duran, B. (2003). The conceptual, historical, and practice roots of community based participatory research and related participatory traditions. In N. W. Meridith Minkler (Ed.), Community-Based Participatory Research for Health (pp. 27-52). San Fransisco, CA: John Wille \& Sons, Inc. 
Box 1: Principles of CBPR and considerations for emancipatory practice.

Principles of CBPR:(Isreal et al., 2003)

1) acknowledge the community as a unit of identity;

2) build on the strengths and resources in the community;

3) facilitate a collaborative, equitable partnership in all phases of the research;

4) foster co-learning and capacity building among all partners;

5) balance knowledge generation and intervention for the mutual benefit of all partners;

6) attend to both local relevance and ecological perspectives;

7) develop systems using a cyclical and iterative process;

8) disseminate results to all partners, and involve all partners in dissemination;

9) commit to a long-term process and group sustainability.

Considerations for facilitating emancipatory practice:(Wallerstein \& Duran, 2003)

1) the meaning and application of "participation;"

2) the basis for knowledge creation including the relationship between knowledge and power;

3) other relevant manifestations of power;

4) praxis as the continuous creation, reflection, and adjustment of processes to attend to participation and power 
Community

KEEPS RESEARCH RESPECTFUL, ACCESSIBLE, AND SOCIALLY RELEVANT

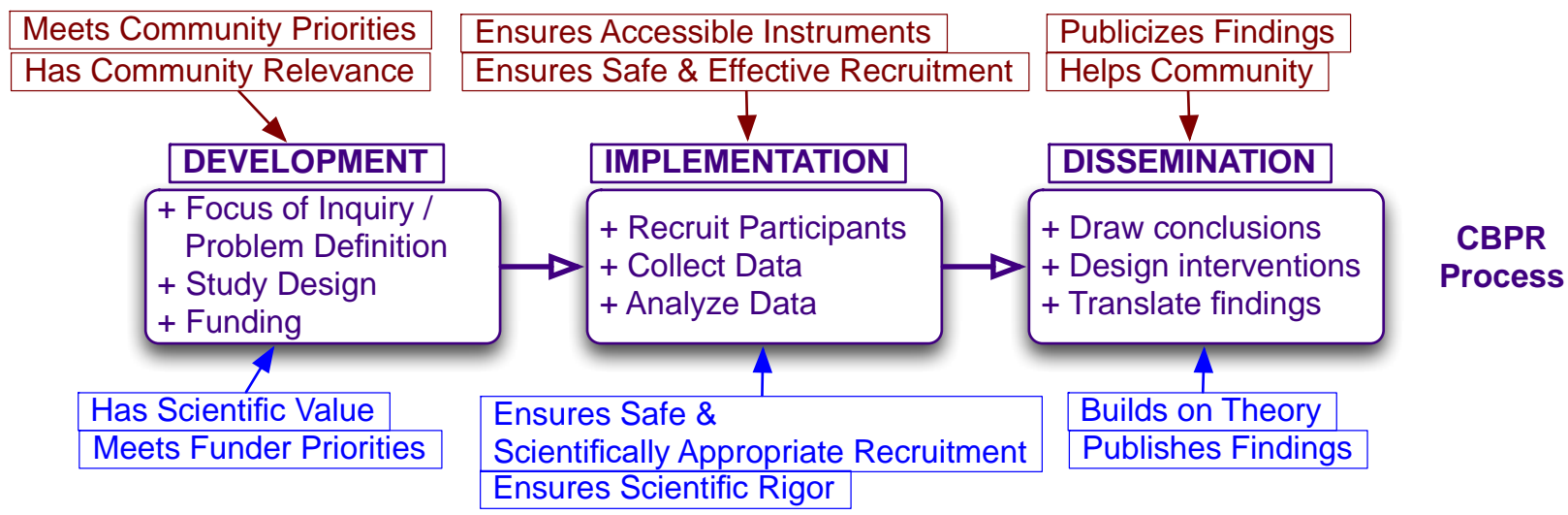

KEEPS RESEARCH SCIENTIFICALLY SOUND AND ACADEMICALLY RELEVANT

Figure 1: CBPR Process

\section{Academics}

Adapted from Nicolaidis, C., Raymaker, D., McDonald, K., Dern, S., Ashkenazy, E., Boisclaire, W. C., ... Baggs, A. (2011). Collaboration strategies in non-traditional CBPR partnerships: lessons from an academic-community partnership with autistic self-advocates. Progress in community health partnerships: research, education, and action, 011:5(2), 143-150. 